\title{
Correction: GW182-Free microRNA Silencing Complex Controls Post-transcriptional Gene Expression during Caenorhabditis elegans Embryogenesis
}

Guillaume Jannot, Pascale Michaud, Miguel Quévillon Huberdeau, Louis Morel-Berryman, James A. Brackbill, Sandra Piquet, Katherine McJunkin, Kotaro Nakanishi, Martin J. Simard

There is an error in the current address for the first author, Guillaume Jannot. 'UMR 7126' should read 'UMR 7216'. The correct current address is: Epigenetics and Cell Fate, Centre National de la Recherche Scientifique (UMR 7216), Université Paris Diderot (Sorbonne Paris Cité), Paris, France.

\section{Reference}

1. Jannot G, Michaud P, Quévillon Huberdeau M, Morel-Berryman L, Brackbill JA, Piquet S, et al. (2016) GW182-Free microRNA Silencing Complex Controls Post-transcriptional Gene Expression during Caenorhabditis elegans Embryogenesis. PLoS Genet 12(12): e1006484. doi:10.1371/journal.pgen. 1006484 PMID: 27935964

\section{G openaccess}

Citation: Jannot G, Michaud P, Quévillon Huberdeau M, Morel-Berryman L, Brackbill JA, Piquet S, et al. (2016) Correction: GW182-Free microRNA Silencing Complex Controls Posttranscriptional Gene Expression during Caenorhabditis elegans Embryogenesis. PLoS Genet 12(12): e1006534. doi:10.1371/journal. pgen. 1006534

Published: December 29, 2016

Copyright: ๑ 2016 Jannot et al. This is an open access article distributed under the terms of the Creative Commons Attribution License, which permits unrestricted use, distribution, and reproduction in any medium, provided the original author and source are credited. 